\title{
Música e literatura: um fenômeno unitário
}

Music and literature: a single phenomenon

\section{Uma entrevista com o maestro Isaac Karabtchevsky}

$\underline{\underline{\text { Júlia Tygel }}}$

1 Doutora em Musicologia (USP, com estágio na City University of New York), é pianista, compositora e Assessora Artística na Osesp. Graduada em Composição e mestre em Etnomusicologia (ambos pela Unicamp), lecionou na Faculdade de Música Souza Lima e no curso de Educação Musical à Distância da Universidade Federal de São Carlos. Atualmente, desenvolve trabalhos autorais de canção, musicando poemas de Manoel de Barros e de seu avô poeta belga Simon Tygel, que foi traduzido do francês por Guilherme de Almeida. 
Regente Titular da Orquestra Sinfônica de Heliópolis - projeto desenvolvido pelo Instituto Baccarelli - Isaac Karabtchevsky é, do alto de suas oito décadas, o mais célebre maestro brasileiro. Atualmente, Diretor Artístico e Regente Titular da Orquestra Petrobras Sinfônica, esteve à frente da Orquestra Sinfônica Brasileira por 26 anos e, no exterior, foi Diretor Artístico da Tonkünstlerorchester, de Viena (1988 a 1994), do Teatro La Fenice, de Veneza (1995 a 2001) e da Orchestre National des Pays de la Loire (2004 a 2010). Convidado habitual da Osesp, gravou com essa orquestra a integral das Sinfonias de Heitor Villa-Lobos - coleção que recebeu, no ano passado, o Grande Prêmio da Revista Concerto e o Prêmio da Música Brasileira.

Minutos antes de reger um concerto do grupo de cordas da Sinfônica de Heliópolis, ele concedeu esta entrevista exclusiva à Revista Literartes.

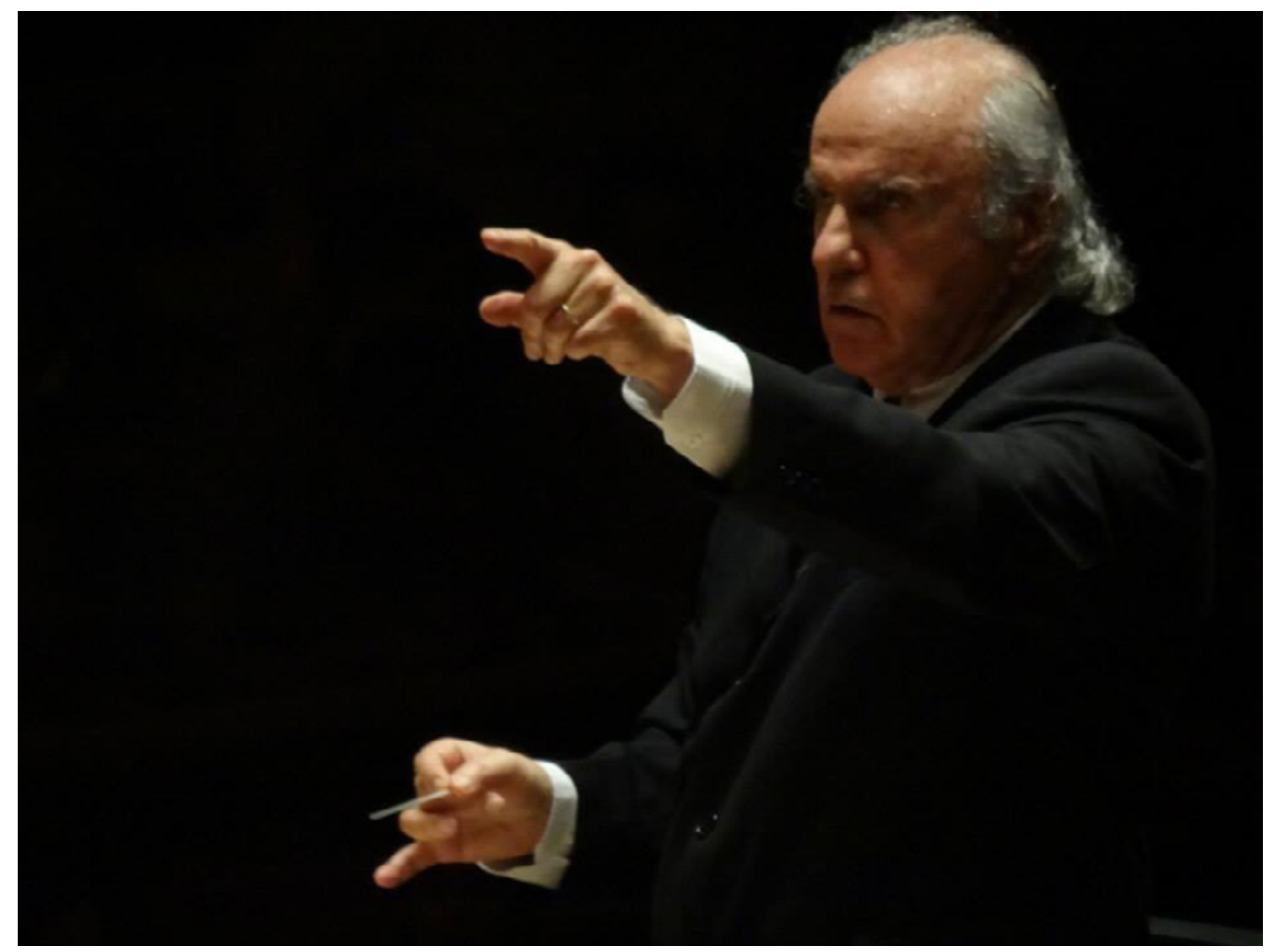

Maestro Isaac Karabtchesky - crédito da foto: Marcelo Werneck/acervo Instituto Baccarelli 
I. O senhor poderia falar um pouco sobre a experiência de ensino de música no Instituto Baccarelli, em Heliópolis, no contexto de que existe uma lei que regula a implementação do ensino de música nas escolas, que não é aplicada pela falta de investimento público? Como a sociedade civil pode contribuir com esse tipo de projeto, quando não há apoio do Estado?

É uma pergunta sem resposta.

2. Como Heliópolis burlou essa falta de apoio?

A função de Heliópolis é, especialmente, a integração dos jovens - especialmente aqueles provenientes de uma zona conturbada, nas comunidades - e integrá-los, recuperar as suas vidas através de um projeto que manifeste, em primeiro lugar, as sensibilidades. Então esse é o nosso escopo: trabalhar o potencial sensitivo dos jovens - que pode se manifestar amplamente através da música, através da pintura ou através de outras artes manuais... mas Heliópolis se dedica especificamente à música, porque nós reconhecemos que, lá, a música é latente: ela está integrada à tradição do jovem, ainda que ele não seja um profissional. Ainda que ele provenha de uma situação de risco, como é Heliópolis, de uma comunidade carente, sem escolas, sem conservatórios especializados em música, ele tem a vocação encerrada em si mesmo. E o que nós temos verificado através dos anos é que, para se reconhecer um talento musical, não é necessário prospectá-lo como se prospecta petróleo, descendo a mil metros de profundidade: o talento do jovem está na superfície. Basta que você ofereça um programa, com início, meio e fim - um programa bem coordenado, com bons professores, com método adequado àquela criança, àquele jovem - e você, de repente, descobre talentos que serão os profissionais da música do futuro. E através desse passo você passa a integrá-los na sociedade. Se não fosse a música, talvez eles estivessem perdidos, ou relacionados a uma atividade marginal. Eu considero esse um trabalho fundamental, que deveria ser exercido, basicamente, em todo o Brasil. 


\section{Mas lá vocês conseguiram implantar isso sem apoio estatal, certo?}

Eu considero que esse é um movimento que deu certo. Nós temos dois edifícios de cinco andares cada um, temos uma estrutura sólida, fisicamente falando, e o resto é a comunidade brasileira que tem que ajudar. Nós temos alguns apoios importantes, estamos vivendo uma época de crise, como aliás todo o país, e esperamos sair logo dela para retomar as atividades com a mesma amplitude de sempre.

\section{Como o senhor vê as conexões entre música e literatura?}

Elas são fundamentais: eu vejo as artes mais como um fenômeno unitário. Quando você espelha o século XVIII e observa a transição entre o Barroco e o Classicismo, a primeira aferição dessa transição é a arquitetura - mas você poderia falar da literatura, da poesia... há tantos fatores que desencadearam os estilos! Os estilos são como esponjas: eles absorvem aquilo que outros fazem e transpõem isso para seu ambiente.

\section{Isso pode ser utilizado tanto na educação musical quanto literária?}

Eu não considero que o mundo seja compartimentado. Eu acho que o mundo é integrado e que nós temos vivido assim até hoje. O Homem vive, acredita no seu destino, na sua forma de agir e de pensar - algumas vezes de forma errada - mas sempre prevalece no Homem o seu instinto para o bem e para o aprimoramento e isso é salutar. Ainda que nós tenhamos sido contaminados por guerras estúpidas (a guerra é sempre estúpida), eu acredito na capacidade do ser humano de se reinventar e de procurar, através da arte, e através da ciência e da tecnologia, um lugar preponderante no universo. 
6. Ainda sobre as conexões entre música e literatura: as cantigas populares podem ser utilizadas como forma de unir os dois universos na educação infantil?

Bom, eu vejo isso em vários aspectos. Uma das peças que vamos executar hoje [Mourão, de Guerra-Peixe] provém da literatura de cordel, que é uma forma de comunicação entre a arte do nordeste brasileiro integrando música e poesia, verso e música. Eu acho que isso está presente em nós: a música não pode ser dissociada do elemento mais musical que é a palavra. E a palavra é... você pode dizer com tantas versões uma simples frase como "eu te amo": falar em pianíssimo, [diz sussurrando] eu te amo; ou berrar EUTE AMO; você pode empregar outras palavras como "liberdade" de tantas formas... são todas conotações musicais que são inseridas no contexto da palavra e do texto. Então é tudo um fenômeno unitário: seus aspectos se integram e se completam.

\section{Acho que esse é um ótimo encerramento para esse texto! $O$ senhor gos-} taria de dizer mais alguma coisa para a Revista Literartes?

Gostaria de dizer que vocês estão exercendo uma atividade muito salutar de procurarem, em intérpretes, as respostas para perguntas que poderiam sugerir uma certa inquietude, no sentido de não haver solução. Eu acho que as artes se completam - e são os artistas que devem responder, em primeiro lugar, por essa associação. 